\title{
Numerical Experiments of a Convective Cloud with a High Cloud Base in Shear Flows
}

\author{
By Masanori Yoshizaki \\ Ocean Research Institute, University of Tokyo \\ (Manuscript received 30 November 1977, in revised form 24 August 1978)
}

\begin{abstract}
A numerical model including dynamical and cloud physical processes is formulated to simulate the observational evidences concerning the severe storms frequently observed in the North American Continent. Our concerns are restricted to five points; (1) generation of a cold dome and a convergence line at the surface, (2) upshear tilting of an updraft, (3) a long-lasting nature, (4) a right-moving convective cloud and (5) generation of vertical vorticity. To examine roles of vertical wind profiles on the above-mentioned features, we make numerical calculation for four cases with different wind profiles.

It is shown that the point (1) can be explained by cooling due to evaporation of raindrops falling in the subcloud layer. In the case for which the direction of the basic wind shear turns with height, a long-lasting nature of the convective cloud, upshear tilting of an updraft and the small deviation of the rain region movement from the environmental wind direction are obtained. The jet type wind plays an important role in (3), because it transports raindrops not to cut off the supply of fresh air from the subcloud layer into the updraft region. Vertical vorticity is created mainly by the tilting term at the developing stage and then the vertical advection and the divergence term as well as the tilting term are principal terms. A pair of strong anticyclonic and weak cyclonic vortices are found in the rain region.
\end{abstract}

\section{Introduction}

Severe thunderstorms are well-known as one of mesoscale disturbances in the United States. Two kinds of thunderstorms are considered; one is the small-to-moderate "air mass" thunderstorm which commonly occurs in the southeastern United States in summer and the other the severe thunderstorm most frequantly found over the Great Plains (Lilly, 1975). As examples of the latter, there are the multi-cell storms, the supercell storms and a variety of the supercell storms in extremely strong shear (Marwitz, $1972 \mathrm{a}, \mathrm{b}, \mathrm{c}$ ) and the squall line storms. We are mainly concerned with the latter thunderstorms and review briefly as follows.

(1) Radar observations: The disorganized "air mass" type echoes are small in size and shortlived. They move in the same direction of the environmental wind. On the contrary, echoes of severe thunderstorms are large and long-lasting, although their shapes change with time. They move to the right of winds at all levels above the cloud base to increase the relative low-level inflow toward the storms (Newton and Fankhauser, 1964; Foote and Fankhauser, 1973; Browning and Foote, 1976). Browning (1964) called them SR (severe right-moving) type storms. However, there are a few cases of left-moving storms (Hammond, 1967; Fujita and Grandoso, 1968; Charba and Sasaki, 1971). As for the characteristic inner structure of the SR type storms, there is a WER (weak echo region) in the right flank of the direction of movement, which is a strong updraft region confirmed by direct measurements using aircrafts (Marwitz, 1973) and Doppler radar (Kropfli and Miller, 1976). The updraft near the WER is also found to be upshear tilting in the linear shear wind. In the right flank of echoes, hook echoes and tornadoes are often observed (Browning and Donaldson, 1963; Fujita, 1965).

(2) Stratification: The stratification of the storm environment is latently unstable in the middle layer and nearly dry-adiabatic in the lower layer (Foote and Fankhauser, 1973; Browning 
and Foote, 1976). It is also important that air in the lower layer is so dry that the cloud base is very high $(1.5 \sim 3 \mathrm{~km}$ above the ground).

(3) Wind: The southerly wind brings moist warm air in the lower layer and the dry westerly wind prevails in the middle and upper layers (Browning, 1964; Newton, 1967). The wind shear is generally strong and turns direction with height.

(4) Surface observations: The precipitating region agrees with a cold, high-pressure, divergent and intense echo region. On the upstream side of the precipitating region is found a convergence line where the wind direction abruptly changes and the pressure jump occurs (Fujita, 1963; Fujita and Grandoso, 1968; Foote and Fankhauser, 1973). The upstream side denotes the windward side of the environmental wind relative to the cloud movement in the subcloud layer.

(5) Observation by aircrafts: Near the cloud base an updraft is rather laminar and extends over several kilometers uniformly; on the contrary, a downdraft in the precipitating region and an updraft in the upper layer are very turbulent (Marwitz and Berry, 1971). Negatively buoyant updrafts are commonly observed (Marwitz, 1973).

(6) Mass and moisture budgets in the subcloud layer: Foote and Fankhauser (1973) calculated mass and moisture budgets in the subcloud layer using data obtained by two aircrafts in the case of Colorado thunderstorm. An averaged vertical motion in the area of about $800 \mathrm{~km}^{2}$ is upward with about $3 \mathrm{~ms}^{-1}$ at the cloud base. Moisture budget analysis in the subcloud layer revealed that only a small portion of the moisture entering the cloud reached the ground as precipitation and thus the storm was inefficient in precipitation. The inefficiency may arise from occurrence of large evaporation in the downdraft in the deep dry subcloud layer.

Our concerns are restricted to five points; (1) generation of a cold dome and a convergence line at the surface, (2) upshear tilting of an updraft, (3) a long-lasting nature of a convective cloud, (4) a right-moving convective cloud and (5) generation of vertical vorticity. In order to make clear these points, life cycles of the convective cloud such as a supercell storm are investigated combining the dry subcloud layer with two wind profiles in the horizontally uniform situation.

As for (1), Fujita (1959) gave an explanation that a cold dome is produced by cooling due to evaporation of raindrops falling in the subcloud layer. According to his explanation, it is expected that the cold dome may be intensified as the height of the cloud base increases. As a dynamical aspect, the downdraft in the subcloud layer and the outflow from the precipitating region may be strong in the case of a cloud with the high cloud base and produce a remarkable convergence line. Since the stratification in the lower layer is nearly dry-adiabatic, an air parcel may be lifted up to the cloud base with small negative buoyancy. It is, therefore, anticipated that new clouds tend to develop above the convergence line. Where and how the convergence line is generated is one concern for simulating a longlasting clouid.

Wind profiles and shear strength are important factors for (2) and (3) (Takeda, 1971; Hane, 1973; Schlesinger, 1973). In order to make clear their role, the wind profiles are devided into two types; one is the linear shear wind and the other the jet type wind. In this paper the linear shear wind denotes the wind whose speed increases monotonically with height and therefore does not always mean a constant shear one. A three-dimensional convective cloud is simulated in the wind veering with height, which is synthesized using the linear shear wind and the jet type wind.

As for (4), Newton and Fankhauser (1964) described the direction of storm motion in relation to storm diameter and pointed out that new convective clouds tend to form on the righthand side of an existing storm of squall lines. They considered the vertical mixing of horizontal momentum in the thunderstorm as an important factor for (4) to form a new cloud. On the contrary, Fujita and Grandoso (1968) and Charba and Sasaki (1971) considered the Magnus effect as a mechanism for (4) and tried to explain the mechanism of splitting echoes and rotating thunderstorms. However, as the supply of fresh air from the subcloud layer into the updraft region is primarily needed to maintain the convective activity, the movement of a convective cloud may follow the movement of the convergence zone in the subcloud layer. Therefore, we are mainly concerned with the movement of the convergence line at the surface, not with the momentum mixing in the cloud and the Magnus effect.

In order to know the mechanism and generation of hook echoes and tornadoes, it is needed to study generation of vertical vorticity and its 
distributions in the cloud. For (5), Fujita and Grandoso (1968) and others considered that generation of vertical vorticity was due to creation of wake flows trailing behind the convective towers, while Schlesinger (1975) showed that in the developing stage it was due to conversion of the horizontal vorticity of ambient wind shear into vertical vorticity in his numerical experiment. In this study vorticity formation is shown not only in the developing stage but also in the later stage.

\section{Model}

\section{a. Equations of motion}

The three-dimensional equation of motion in Cartesian coordinates and vector form is

$$
\begin{aligned}
& \frac{\partial \boldsymbol{V}}{\partial t}=-(\boldsymbol{V} \cdot \nabla) \boldsymbol{V}-c_{p} \bar{\theta} \nabla \pi^{\prime} \\
& \quad+\boldsymbol{k} g\left(\frac{\theta^{\prime}}{\bar{\theta}}+0.61 Q_{v^{\prime}}-Q_{c}-Q_{r}\right)+K V^{2} \boldsymbol{V}^{\prime}
\end{aligned}
$$

where $\nabla$ is the three-dimensional del operator, $\nabla^{2}$ the Laplacian operator, $\boldsymbol{V}$ the three-dimensional velocity vector, $c_{p}$ the specific heat of dry air at constant pressure, $\theta$ the potential temperature, $Q_{v}$ the mixing ratio of water vapour, $Q_{c}$ the mixing ratio of cloud droplets and $Q_{r}$ the mixing ratio of raindrops; $\pi=(p / P)^{R / c} p$, the nondimensional pressure, where $p$ is the pressure, $P$ the reference pressure $(=1,000 \mathrm{mb})$ and $R$ the gas constant for dry air. The overbar denotes basic state which is the function of the vertical coordinate $z$ alone, and the dashed value is the deviation from it. The diffusion coefficient $K$ is constant for simplicity as $200 \mathrm{~m}^{2} \mathrm{~s}^{-1}$. Note that only the diffusion of the deviation parts is included. The continuity equation is given as

$$
D \equiv \nabla(\rho \boldsymbol{V})=0 \text {. }
$$

The pressure as the diagnostic quantity can be determined from (1) as follows,

$$
\begin{aligned}
& c_{p} \nabla\left(\bar{\rho} \bar{\theta} \nabla \pi^{\prime}\right)=-\nabla\left[\bar{\rho}(\boldsymbol{V} \cdot \nabla) \boldsymbol{V}-\bar{\rho} K \nabla^{2} \boldsymbol{V}^{\prime}\right] \\
& \quad+\frac{\partial}{\partial z}\left[\bar{\rho} g\left(\frac{\theta^{\prime}}{\bar{\theta}}+0.61 Q_{v}{ }^{\prime}-Q_{c}-Q_{r}\right)-\frac{\partial D}{\partial t} .\right.
\end{aligned}
$$

The last term in (3) must vanish by (2), but does not vanish exactly because of computational round-off errors. Therefore, we adopt the technique proposed by Harlow and Welsh (1965) in order to keep the mass conservation. The method for solving (3) is referred ot Williams (1969).

\section{b. Equations of the potential temperature and water}

Water substance is divided into three forms as water vapor, cloud droplets and raindrops. These last two liquid forms of water are classified by whether they are advected alone by the wind or fall down by their weights. The parameterization of cloud physics is almost the same as that of Soong and Ogura (1973) and Wilhelmson (1974). Equations of the potential temperature and water are

$$
\begin{aligned}
& \frac{\partial \theta}{\partial t}=-(V \cdot \nabla) \theta+\frac{L}{c_{p} \bar{\pi}}(P 2-P 3-P 4) \\
& \quad+K V^{2} \theta^{\prime} \\
& \frac{\partial Q_{v}}{\partial t}=-(V \cdot \nabla) Q_{v}-P 2+P 3+P 4+K V^{2} Q_{v^{\prime}} \\
& \frac{\partial Q_{c}}{\partial t}=-(V \cdot \nabla) Q_{c}-k_{1}\left(Q_{c}-a\right)-k_{2} Q_{c} Q_{r}{ }^{0.875} \\
& \quad+P 2-P 3+K V^{2} Q_{c} \\
& \frac{\partial Q_{r}}{\partial t}=-(V \cdot \nabla) Q_{r}+\frac{\partial}{\partial z}\left(V_{r} Q_{r}\right)+V_{r} Q_{r} \frac{1}{\bar{\rho}} \frac{\partial \bar{\rho}}{\partial z} \\
& \quad+k_{1}\left(Q_{c}-a\right)+k_{2} Q_{c} Q_{r} r^{0.875}-P 4
\end{aligned}
$$

where $L$ is the latent heat of water vapour, P2 the rate of condensation, $\mathrm{P} 3$ the evaporation rate of cloud droplets, $\mathrm{P} 4$ the evaporation rate of raindrops and $V_{r}$ the terminal velocity of raindrops. The autoconversion parameter $k_{1}, a$, and the collection parameter $k_{2}$ are defined as $k_{1}=0$ for $Q_{c}<a, k_{1}=10^{-3} \mathrm{~s}^{-1}$ for $Q_{c}>a, a=0.5 \mathrm{~g} \mathrm{~kg}^{-1}$, and $k_{2}=2.2$. The terminal velocity $V_{r}$ is chosen as $4.5 \times\left(Q_{r}\right)^{1 / 2} \mathrm{~ms}^{-1}$ for $Q_{r}<4 \mathrm{~g} \mathrm{~kg}^{-1}$ and $9 \mathrm{~ms}^{-1}$ for $Q_{r} \geqq 4 \mathrm{~g} \mathrm{~kg}^{-1}$ following Takeda (1965). P2 represents the rate of condensation which occurs in the supersaturated region, calculated by the equations formulated by Asai (1965). P3 and P4 are the evaporation rate of cloud droplets which takes place in the unsaturated region instantaneously and the evaporation rate of raindrops, formulated as

$$
P 4=\beta\left(Q_{v s}-Q_{v}\right) \text { when } Q_{v s}>Q_{v} \text { and } Q_{r}>0
$$

where $Q_{v s}$ represents the saturation mixing ratio and $\beta$ the evaporation parameter of raindrops. The parameter $\beta$ affects very sensitively the life cycle of the convection, in particular, the magnitude of the downdraft due to raindrops. The value of $\beta$ is selected as $10^{-3} \mathrm{sec}^{-1}$ in this study. The radiational effect and the parameterization of the solid state of water are neglected.

\section{c. Boundary conditions}

At the top and bottom boundaries, the vertical velocity $w$ and the vertical gradient of horizontal velocities are assumed to vanish, i.e., 


$$
\left.\begin{array}{l}
\begin{array}{l}
w=0 \\
\frac{\partial}{\partial z}
\end{array}(u, v)=0
\end{array}\right\} \text { at } z=0 \text { and } Z
$$

The other variable A such as $\theta^{\prime}, Q_{v}{ }^{\prime}, Q_{c}$ and $Q_{r}$ is assumed as

$$
\frac{\partial A}{\partial z}=0 \quad \text { at } z=0 \text { and } Z
$$

From (9), the upper and lower conditions for the equation (3) are given by

$$
\frac{\partial \pi^{\prime}}{\partial z}=g\left(\frac{\theta^{\prime}}{\bar{\theta}}+0.61 Q_{r}{ }^{\prime}-Q_{c}-Q_{r}\right) / c_{p} \bar{\theta}
$$

For the lateral boundaries, we use a closed and slip condition which can be described as follows;

$$
u^{\prime}=0, \quad \frac{\partial v^{\prime}}{\partial x}=\frac{\partial w}{\partial x}=0 \quad \text { at } x=0 \text { and } X
$$

and

$$
v^{\prime}=0, \quad \frac{\partial u^{\prime}}{\partial y}=\frac{\partial w}{\partial y}=0 \quad \text { at } y=0 \text { and } Y
$$

Note that the normal wind velocity remains constant and only the deviation part should vanish at the lateral boundaries. For the other variable A, the lateral boundary conditions are assumed as follows. In the case of inflow and no flow, the horizontal gradient is

$$
\frac{\partial A}{\partial n}=0 \text { at }\left\{\begin{array}{l}
x=0 \text { and } X \text { when } n=x \\
y=0 \text { and } Y \text { when } n=y
\end{array}\right\}
$$

In the case of outflow, it is

$$
\frac{\partial^{2} A}{\partial n^{2}}=0 \text { at }\left\{\begin{array}{l}
x=0 \text { and } X \text { when } n=x \\
y=0 \text { and } Y \text { when } n=y
\end{array}\right\}
$$

Since A is not defined on the boundaries (Fig. 1), this condition is assumed to be replaced in a difference form in the case of $n=x$ and at $x=X$ by

$$
A_{N x-1}-2 A_{N x}+A_{N x+1}=0
$$

where $A_{N x}$ and $A_{N x-1}$ are known values in the calculation domain while $A_{N x+1}$ is unknown value outside of the domain. The other cases $(n=x$

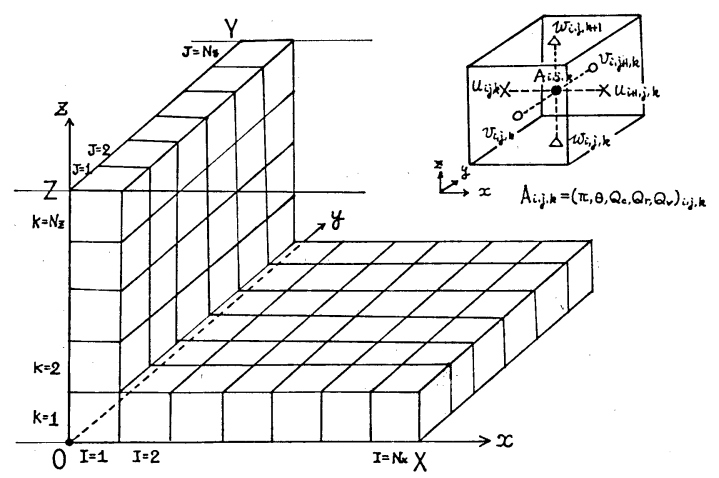

Fig. 1 Three-dimensional staggered grid configuration for one grid cell and the whole calculation domain. $X, Y$ and $Z$ represent the boundaries in $x, y$ and $z$ directions respectively.

Table 1. Values of parameters in each case. $L$ and $J$ mean the linear type and the jet type winds, respectively. $\Delta(\quad)$ and $\mathrm{Ni}$ denote the grid size and the grid number in the $i$ direction. $X$ and $Y$ are the widths of the domain in the $x$ and $y$ direction, respectively. $r_{c}, r_{0}$ and $z_{c}$ are defined such as (16) in order to give the domain of the initial impulse.

\begin{tabular}{lccccc}
\hline & & \multicolumn{2}{c}{ 2-dim. } & \multicolumn{2}{c}{ 3-dim. } \\
\hline \multirow{2}{*}{ basic wind } & case & 21 & 22 & 31 & 33 \\
\cline { 3 - 6 } & & $L$ & $J$ & $L$ & $L+J$ \\
\hline grid & & & & & \\
& $\Delta x(\mathrm{~m})$ & 500 & 500 & 600 & 1,000 \\
& $\Delta y(\mathrm{~m})$ & - & - & 600 & 1,000 \\
& $N x$ & 100 & 100 & 50 & 30 \\
& $N y$ & - & - & 20 & 30 \\
& $X(\mathrm{~km})$ & 50 & 50 & 30 & 30 \\
& $Y(\mathrm{~km})$ & - & - & 12 & 30 \\
\hline \multicolumn{7}{l}{ initial impulse } & & & & \\
& $r_{c}(\mathrm{~km})$ & 25 & 25 & 15 & 15 \\
& $r_{0}(\mathrm{~km})$ & 2 & 2 & 2.4 & 3 \\
& $z_{c}(\mathrm{~km})$ & 2.25 & 2.25 & 2.25 & 2.25 \\
\hline
\end{tabular}


at $x=0 ; n=y$ at $y=0 ; n=y$ at $y=Y$ ) are treated in the same way. These conditions given by Takeda (1971) indicate that although it is closed for the kinetic energy, the domain is open for potential temperature and water and the boundaries are, in a sense, passive because the variables on them are determined by the inner values.

Note that the symmetric condition about the $x z$-plane is assumed at $y=Y$ for the case 31 (Table 1), because the basic wind is unidirectional, i.e., $\bar{u}(z)$.

\section{d. Schemes}

Velocity components are arranged staggered (Fig. 1) and the other variables are defined at the center of the box. The grid interval is fixed as $500 \mathrm{~m}$ in the vertical coordinate and varies in the horizontal coordinates (Table 1) in some cases. This leads to difficulty of quantitative comparison with each other, but we are mainly concerned with the qualitative behaviours of convections. Total number of grid points is $N_{x} \times N_{y} \times N_{z}$ in a three-dimensional model and $N_{x} \times N_{z}$ in a twodimensional model where $N_{i}$ represents the number of grid points in $i$-coordinate. As for $N_{z}$, the top boundary must be high enough if excited gravity waves above the convective layer play dominant roles in the development and maintenance of convections. But we assume that these waves have little effect on convections and are preferable to be excluded for the computational stability. Then, the height of the top boundary is fixed as $Z=10 \mathrm{~km}$ and $N_{z}=20$. The pressure and diffusion terms are calculated using centered differences. While advective terms of velocities are obtained using an upstream space differencing, the remaining advective terms such as potential temperature and water are calculated by a modified upstream differencing proposed by Soong and Ogura (1973) which is based on the flux form. For the time integration, we employ the mixed scheme of the forward-time and Eulerbackward schemes. When the form of the internal gravity waves is given by $\mathrm{e}^{i \omega t}$ and time increment is $\Delta t$, the amplification factor of this scheme is $\left\{1+(\omega \Delta t)^{6}\right\}^{1 / 4}$, or approximately $1+1 / 4(\omega \Delta t)^{6}$ if $\omega \Delta t \ll 1$. This means that the scheme is unstable for the internal gravity waves but amplifies more slowly than the forward-time scheme alone for which the amplification factor is $\left\{1+(\omega \Delta t)^{2}\right\}^{1 / 2}$. Owing to this small amplification, the diffusive effect of the upstream scheme and large diffusion coefficients, the time integration can be done for long time steps without any trouble of amplifying internal gravity waves. The increment $\Delta t=10$ sec is adopted in this study.

\section{e. The basic state and initial conditions}

The basic stratification and the basic wind profiles are shown in Figs. 2 and 3. The basic temperature lapse rate changes from $9.0 \mathrm{~K} \mathrm{~km}^{-1}$ below $z=3 \mathrm{~km}$ to $6.0 \mathrm{~K} \mathrm{~km}^{-1}$ above it. The basic humidity changes linearly from $50 \%$ at
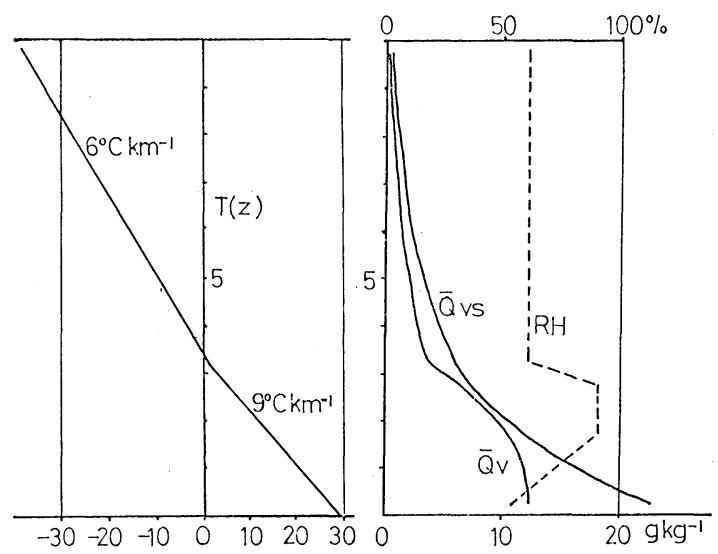

Fig. 2 The vertical profiles of the basic atmospheric layer; (a) the basic temperature $T$ and (b) the relative humidity $\mathrm{RH}$, the mixing ratio of vapour $Q v$ and the saturated mixing ratio Qvs.

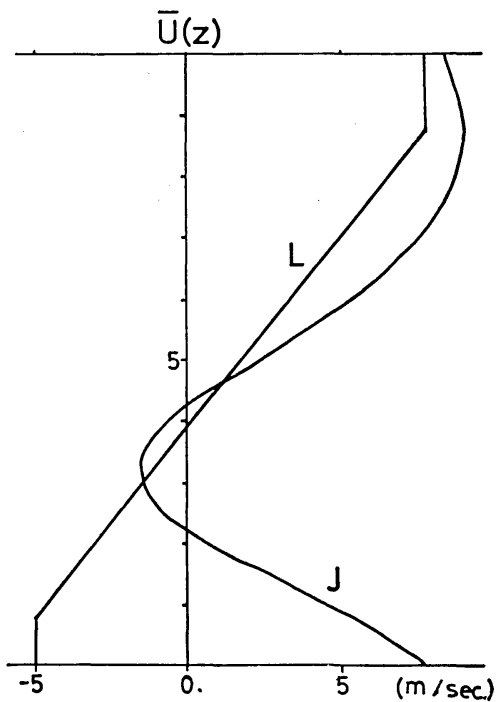

Fig. 3 The vertical profiles of the basic winds. $L$ and $J$ represent the linear shear wind and the jet type wind respectively. 
the surface to $90 \%$ at $z=1.75 \mathrm{~km}$ and keeps constant as $90 \%$ up to $z=3 \mathrm{~km}$. Above $z=3 \mathrm{~km}$ it is constant as $60 \%$. This stratification provides a nearly dry-adiabatic and dry layer below cloud base at the height $z=1.75 \mathrm{~km}$.

Two types of wind profiles such as the linear type $L$ and the jet type $J$ (Fig. 3) are considered in order to know their role on transport and distribution of raindrops. In case 33 the basic wind is assumed to have the $L$-type wind in the $x$ direction and the $J$-type wind in the $y$ direction.

The initial impulse is given in the domain $r_{c}-r_{0}<r<r_{c}+r_{0}$ and $z_{c}-\Delta z<z<z_{c}+\Delta z$ as follows,

$$
\theta^{\prime}=T_{i}\left(1-\frac{\left|z-z_{c}\right|}{2 \Delta z}\right) \cos \left(\frac{\pi}{2} \frac{r-r_{c}}{r_{0}}\right)
$$

where $r_{c}, r_{o}$ and $z_{c}$ are listed in Table 1 and $T_{i}=$ $0.5 \mathrm{~K}$. The initial relative humidity in this domain is assumed to be $100 \%$ and no cloud water exists initially.

\section{Results of the two-dimensional model}

\section{a. Life cycle of convective clouds}

The life cycles of convective clouds in the linear type wind (case 21) and in the jet type wind (case 22) are shown in Fig. 4. The maximum values of $W, \theta^{\prime}, Q_{r}$ and minimum value of $W$ in the domain are given as a function with time, denoted by $W_{\max }, \theta_{\max }, Q r_{\max }$ and $W_{\min }$, respectively. For case $21 W_{\max }$ increases till $20.0 \mathrm{~min}$, reaching $17.9 \mathrm{~ms}^{-1}$ and then decreases monotonically. $\left|W_{\min }\right|$ has two peaks; the first peak at $19.0 \mathrm{~min}$ is caused by the compensation of the updraft and the second at $36.0 \mathrm{~min}$ by the downdraft due to raindrops. $Q_{r \max }$ increases from
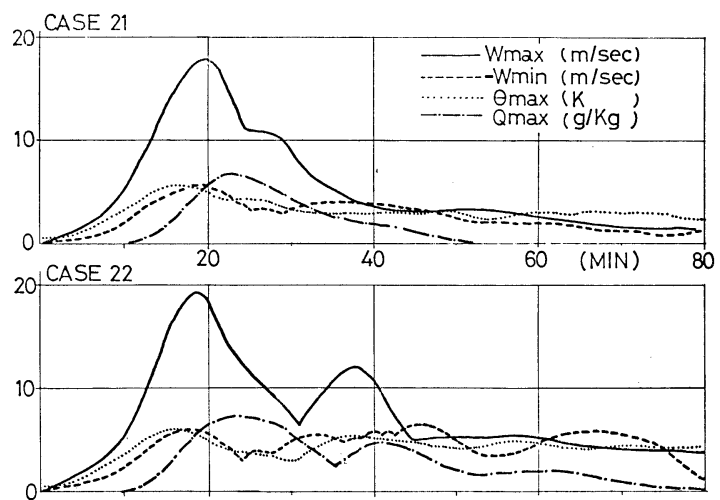

Fig. 4 The variation with time of $W_{\max }$ (solid), $\left|W_{\min }\right|$ (dashed), $\theta_{\max }$ (dotted) and $Q r_{\max }$ (dash dotted) in case 21 and case 22 .

$5.0 \mathrm{~min}$ to $23.0 \mathrm{~min}$, reaching $6.8 \mathrm{~g} \mathrm{~kg}^{-1}$ and the peak of $\theta_{\max }$ is found at $16.0 \mathrm{~min}$.

On the contrary, $W_{\max }$ for case 22 has two peaks at $18.5 \mathrm{~min}$ and at $37.5 \mathrm{~min}$ and reaches a nearly steady state after $45.0 \mathrm{~min}$ with a value of about $5 \mathrm{~ms}^{-1}$. The behaviours of $Q_{r \max }$ and $\theta_{\max }$ have a similar trend to $W_{\max }$, but $\left|W_{\min }\right|$ shows more complicated variation. The state with a almost constant value of $W_{\max }$ might correspond to a long-lasting state.

\section{b. Case 21}

Figs. 5 and 6 show the wind vectors and the contour lines of $Q_{c}, Q_{r}$ and $\theta^{\prime}$ at $17.5 \mathrm{~min}$ and at $35.0 \mathrm{~min}$. The solid and the dashed lines represent the contour lines of $\theta^{\prime}$ and $Q_{c}$ respectively. The region of $Q_{r}$ greater than $1.0 \mathrm{~g} \mathrm{~kg}^{-1}$ is shaded, which is thereafter called a rain region. In the developing stage at $17.5 \mathrm{~min}$ the convec-

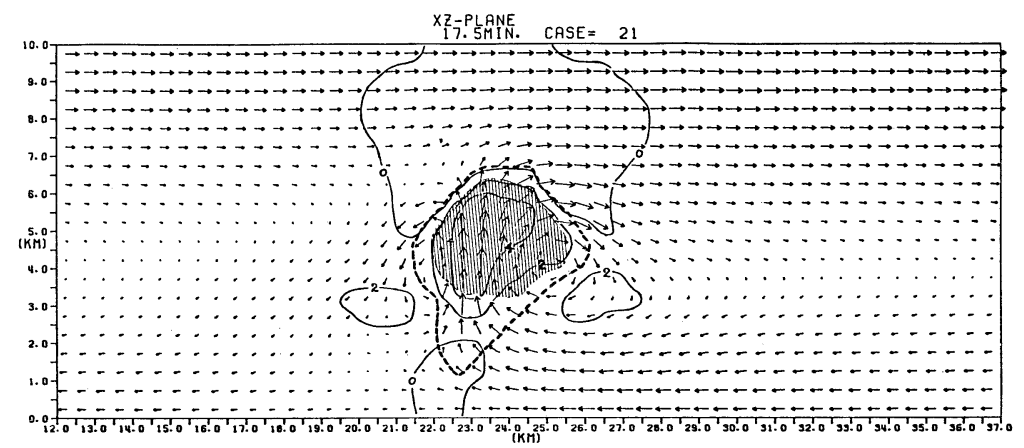

Fig. 5 Contours of $\theta^{\prime}$ (solid) in $K, Q c>0 \mathrm{gkg}^{-1}$ (dashed) and $Q r>$ $1.0 \mathrm{gkg}^{-1}$ (shaded) and wind vectors in the $x z$-plane at 17.5 $\min$ in case 21 . 


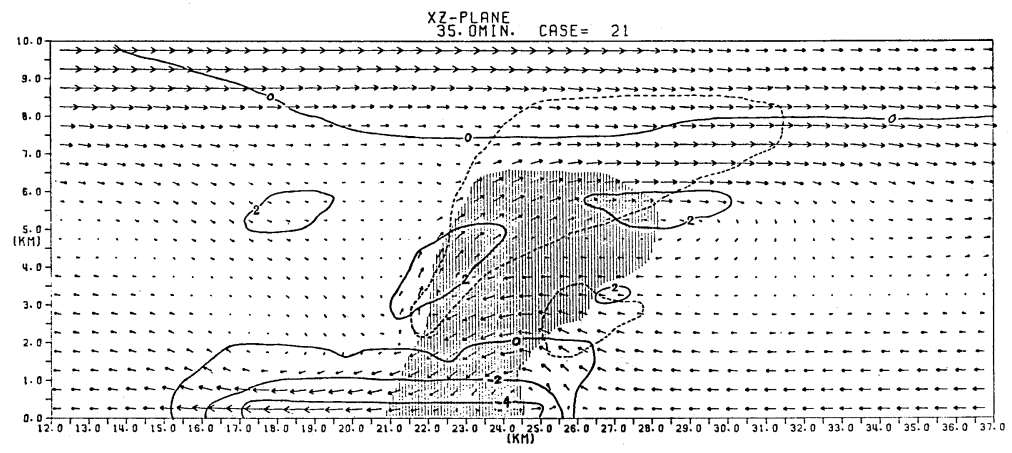

Fig. 6 As in Fig. 5 except at $35.0 \mathrm{~min}$.

tive cloud stands upright against the shear flow and fresh air is supplied from the subcloud layer into the cloud. The positive values of $\theta^{\prime}$ are found in the cloud having the maximum value of $5.7 \mathrm{~K}$ and also in the middle layer of the environment. The former is caused by condensation heating and the latter by adiabatic warming due to compensating downward motion. The negative values are seen below the cloud base and above the cloud top due to forced upward motion. The raindrops are concentrated in the cloud.

In the decaying stage at $35.0 \mathrm{~min}$ the original cloud is found in the upper left portion of the rain region, accompanying a weak updraft (Fig. 6). The updraft tilts downshear, into which no fresh air is supplied from the subcloud layer. Raindrops fall down in the downdraft region and cut off the major supply of fresh air from the subcloud layer into the updraft. In the subcloud layer are found a cold dome and outflows which spread in both sides of the downdraft. The strong leftward outflow and the weak rightward outflow are caused by horizontal divergence associated with the downdraft. This rightward outflow forms a remarkable convergence zone near $x=26 \mathrm{~km}$ and a small new cloud is found above it. This remarkable convergence zone on the upstream side of the precipitating region is thereafter called the convergence line. The cold dome is seen only below the cloud base and there is a small variation of potential temperature near the cloud base. This small variation was reported by an aircraft observation (Fujita, 1959). It is noticed that the cold dome is produced by cooling due to evaporation of raindrops falling in the subcloud layer.

Upshear tilting of the updraft and a long-lasting nature are not obtained in this case. These results conflict with those of Hane (1973). While convective clouds simulated by Hane develop newly and have an upshear tilting updraft in the lower layer, those simulated by Takeda (1971), Wilhelmson (1974) and us do not develop newly and have a downshear tilting updraft. Hane showed that there were sometimes long quiet periods between developments, and that in the developing stage the updraft tilted upshear but in the quiet period downshear. Takeda, Wilhelmson and we simulated only one life cycles of a cloud and did not obtained the development of new clouds. Then Takeda stressed a jet type wind as an important factor for (2) and (3). From the results of Hane and those of Takeda, Wilhelmson and us a newly developed cloud has an upshear tilting updraft in the lower layer and the difference between them may come from whether new convective clouds can develop or not. One of reasons for this difference may be ascribed to the differences of the shear magnitude and of inflow boundary conditions for potential temperature and water substance. The shear winds used by Hane are strong compared with those of Takeda, Wilhelmson and us. While Hane fixed the boundary values as constant, Takeda and we used the condition that the horizontal gradient vanished and Wilhelmson the cyclic condition. Since in the case of Hane more water vapour comes through the lateral boundary by the horizontal advection than in the cases of the latters, new convective clouds can develop more easily.

\section{c. Case 22}

In the developing stage the convection pattern is similar to Fig. 5 except the environmental wind (not shown).

At 35.0 min the cloud tilts rightward and has an updraft on the left side and a downdraft on the right (Fig. 7). Raindrops transported by the wind fall down to the right of the updraft so 


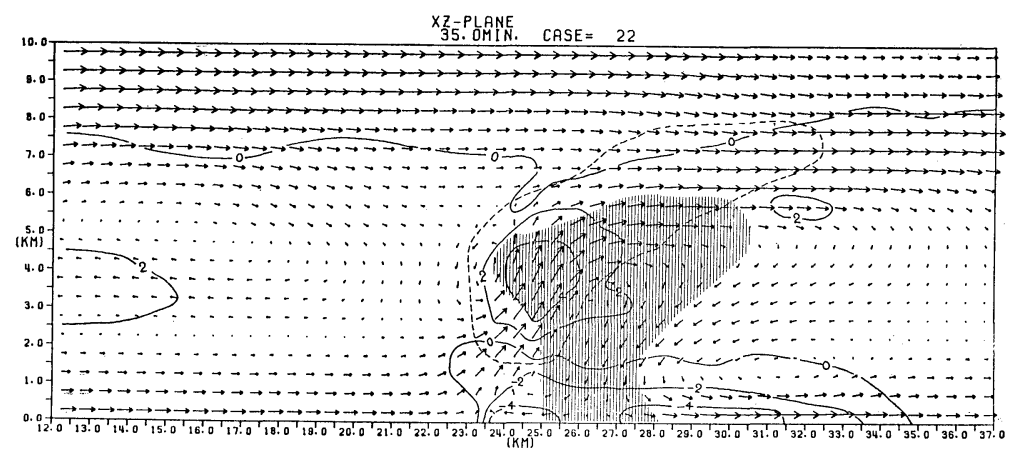

Fig. 7 As in Fig. 5 except at $35.0 \mathrm{~min}$ and in case 22.

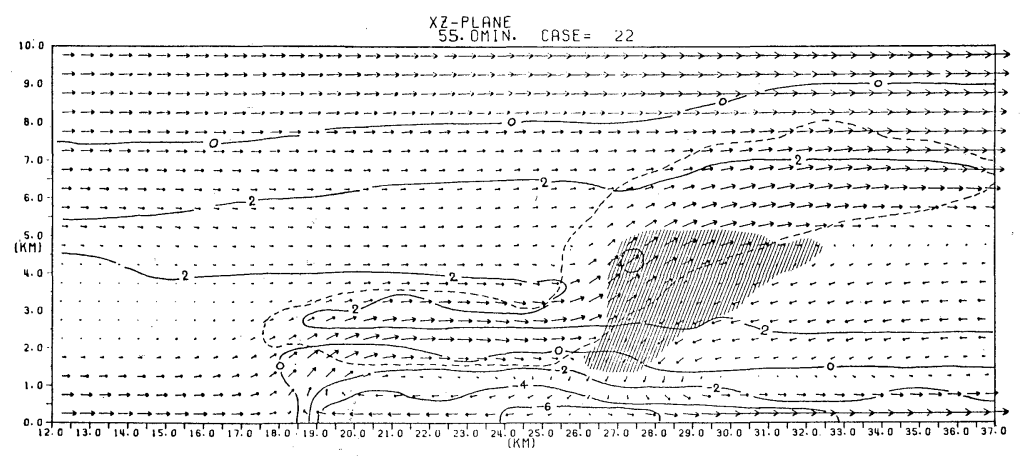

Fig. 8 As in Fig. 7 except at $55.0 \mathrm{~min}$.

as to keep the supply of fresh air from the subcloud layer into the updraft region. The cold dome in the subcloud layer is found in the both sides of the precipitating region and the updraft in the subcloud layer is induced near the convergence line, though negative buoyancy works there.

As the jet profile in case 22 is different from C9 in Takeda (1971) especially in the subcloud layer, there are several different results. The time variation of $W_{\max }$ in Takeda's experiment has only one broad peak, while there are at least two peaks in this case. Although the rightward tilting updraft is found in the left of the downdraft in this experiment, his results showed a leftward tilting updraft.

Since the downdraft generated by raindrops does not cut off the supply of fresh air into the updraft in this case, the cloud has very different behaviours from that in case 21 . At $55.0 \mathrm{~min}$ (Fig. 8) a shelf-like cloud and the convergence line far separated from the rain region are found. These were not seen in case 21 and also in the cases with the low cloud base by Takeda. Owing to the strong downdraft the leftward outflow seemingly pushes the convergence line to the left and then occurs the separation of the convergence line from the rain region. The temperature gradient near the convergence line is very large at the surface. This is similar to the temperature break shown by Fujita (1963) and Foote and Fankhauser (1973). It is noticed that the positive regions of $\theta^{\prime}$ greater than $2 \mathrm{~K}$ cover almost whole the middle layer, indicating that the stratification becomes stable and that the inversion layer is generated between the middle and the lower layers.

Generation of a cold dome with a pressure rise and a convergence line (1) can be simulated by cooling due to evaporation of raindrops falling in the subcloud layer. This has been already given by Fujita (1959). Upshear tilting of an updraft (2) and a long-lasting nature (3) are attained only in the jet type wind as shown by Takeda (1971). It is known from cases 21 and 22 that the long-lasting nature is mainly dependent on where raindrops are transported by the wind and then fall down. The jet type wind plays an important role in transporting raindrops so as not to cut the supply of fresh air into the updraft region. However, upshear tilting of an updraft was frequently observed in the linear 
shear wind (Kropfli and Miller, 1976; Browning and Foote, 1976), which can not be obtained in this two-dimensional model. For (4) and (5), this model does not give any information and hence a three-dimensional model is needed to make clear above-mentioned points.

\section{Results of the three-dimensional model}

\section{a. Case 31}

Fig. 9 shows the time variation of $W_{\max }$, $\mid W_{\min \mid}, \theta_{\max }$ and $Q_{r \max }$ in case 31 . The peak of $W_{\max }$ is found at $18.0 \mathrm{~min}$ reaching $29.2 \mathrm{~ms}^{-1}$

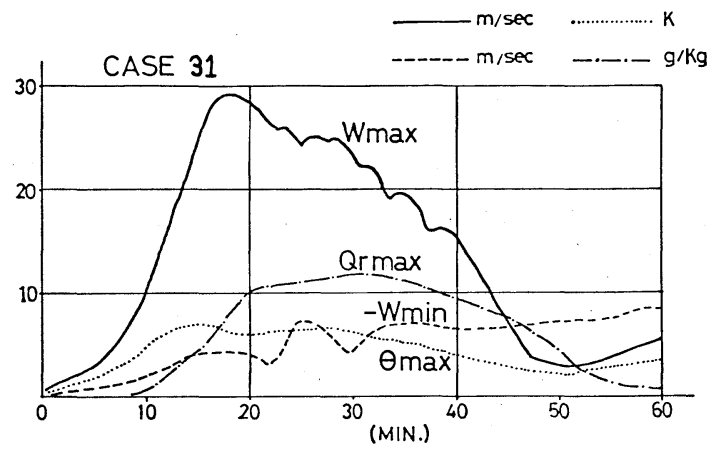

Fig. 9 As in Fig. 4 except in case 31. and $W_{\max }$ decreases more slowly compared with that in case 21. Although the horizontal grid size is larger in this case than in case 21 , the maximum value of $W_{\max }$ is larger by 1.6 times than that in case 21 . This result agrees with the comparison between the two-dimensional and the three-dimensional models by Wilhelmson (1974). $\left|W_{\min }\right|$ increases gradually to $20 \mathrm{~min}$ due to the compensation of an updraft, and the ratio of $\left|W_{\min }\right|$ to $W_{\max }$ is very small compared with that in case 21. After $22 \mathrm{~min}\left|W_{\min }\right|$ is mainly determined by the downdraft due to raindrops and it increases monotonically after $30 \mathrm{~min}$. $Q_{r \max }$ increases rapidly from $8 \mathrm{~min}$ to $20 \mathrm{~min}$ and has a broad peak until $40 \mathrm{~min}$. The time variations of these cloud parameters have similar trends to those of Wilhelmson and of case 21 except that these parameters have no sharp peaks.

In the developing stage, the convection pattern is similar to that in case 21 (not shown). At 40.0 min are shown the wind vectors and the contour lines of $\theta^{\prime}, Q_{c}$ and $Q_{r}$ in the $x z$-plane at $y=12$ $\mathrm{km}$, where the symmetric boundary condition is applied (Fig. 10). The updraft in the original cloud is not so inclined downshear and the downdraft is found on its right. A cold dome expands

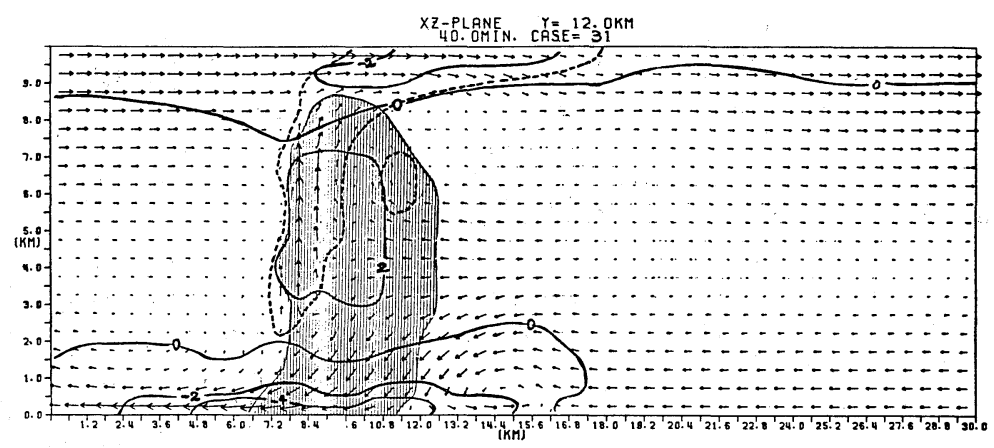

Fig. 10 As in Fig. 5 except at $40.0 \mathrm{~min}$ in the $x z$-plane at $y=12.0 \mathrm{~km}$ in case 31 .

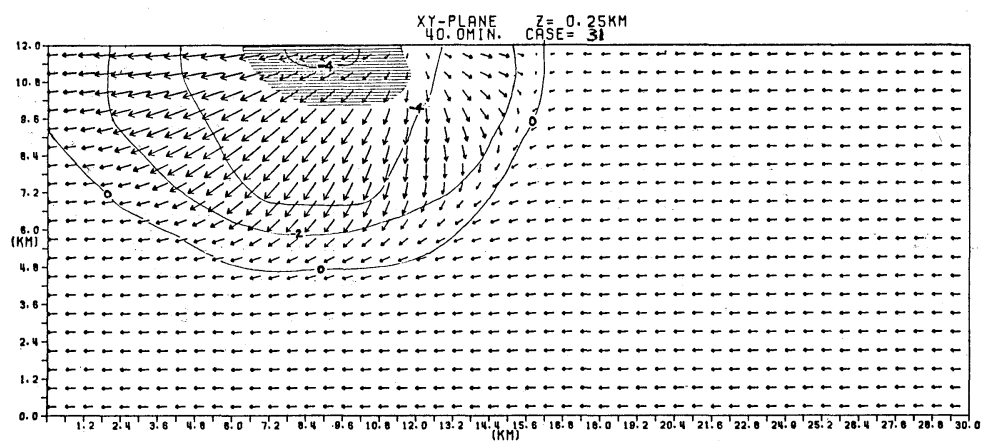

Fig. 11. As in Fig. 10 except at $z=0.25 \mathrm{~km}$ in the $x y$-plane. 
in the both sides of the precipitating region and a small circulation near the convergence line is remarkable. The behaviours of the updraft, the downdraft and the cold dome are similar to those in case 21.

Fig. 11 presents the wind vectors and the contour lines of $\theta^{\prime}, Q_{c}$ and $Q_{r}$ in the $x y$-plane at $z=0.25 \mathrm{~km}$ at $40.0 \mathrm{~min}$. The outflow and the cold dome are remarkable and the arc-shaped convergence line is seen along the line of $\theta^{\prime}=0$ on the upstream side of the precipitating region.

The convective cloud obtained in case 31 is one of "air mass" type thunderstorm and not a long-lasting one. In the case of the linear type wind similar results are obtained in the twodimensional and the three-dimensional models to each other.

\section{b. Case 33}

In this case the convective cloud in the wind shear turning direction with height is investigated. As already mentioned, the wind shear veering with height is frequently observed in the environment where severe storms occur. In Fig. 12(a) the wind hodograph of the hailstorm studied by Foote and Fankhauser (1973) is shown by a thick solid line. Scale is in $\mathrm{ms}^{-1}$, height in $\mathrm{km} \mathrm{MSL}$ and the cloud top and the cloud base are marked with crosses $x$. Storm motion is represented by $V_{e}$ and deviates rightward against the environmental wind. We assume that the friction at the surface does not affect the dynamics in the cloud so seriously and that no horizontal gradient of potential temperature and water vapour exists. These two assumptions are satisfied in this study because of the slip condition at the surface and the horizontally uniform model. Then, in such a situation satisfied with two assumptions, the dynamics in the cloud may not be changed on the coordinate system moving with a constant speed. We take the coordinate system $(x, y)$ moving with a constant speed $V_{o}$. The directions of $x$ and $y$ axes represented by thin dashed lines are determined as the direction in which the linear shear is dominant and the direction normal to $x$, respectively. Therefore the direction of $x$ does not always point toward the east. When the wind profile is represented by a thick dashed line in Fig. 12(a), it seemingly consists of the linear type wind in the $x$ direction and the jet type wind in the $y$ direction. In Fig. 12(b) is shown the wind hodograph used in case 33 which is synthesized using the $L$-type wind in the $x$ direction and the $J$-type wind in the $y$ direction in Fig. 3. Compared the wind in Fig. 12(b) with
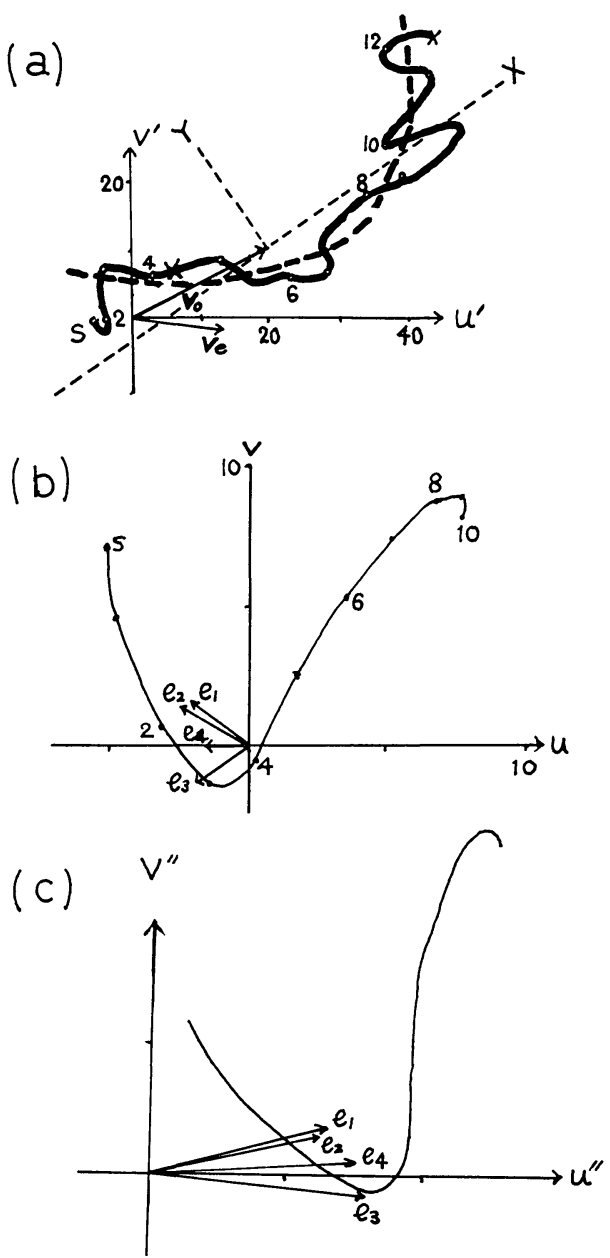

Fig. 12 The wind hodographs. Scale is in $\mathrm{ms}^{-1}$, height in $\mathrm{km}$ MSL and the cloud base and the cloud top are marked with an $X . S$ denotes the surface. (a) The wind hodograph in the hailstorm studied by Foote and Fankhauser (1973) is shown by a thick solid line. $V e$ represents storm motion. The wind hodograph simplified is shown by a thick dashed line and the coordinate system which we take on by thin dashed lines. The coordinate system is moving with a constant speed $V o$ and the direction of $x$ does not always point toward the east. (b) The wind hodograph used in case 33 and the velocity vectors of the position with the maximum amount of raindrops are shown. (c) The wind hodograph observed on the ground and the velocity vectors are shown.

that in Fig. 12(a), the magnitude of the wind in Fig. 12(b) is very small. If the wind in the subcloud layer is strong, influences of the lateral 
boundaries would appear very soon in the numerical calculation, because the outflow is so strong that it reaches the lateral boundaries for a short period. In order to perform numerical calculation for a long time without a significant influence due to the lateral boundaries, a rather weak wind is considered in this study. Vectors represented by $e_{1}, e_{2}, e_{3}$ and $e_{4}$ in Fig. 12(b) correspond to the velocity vectors of the position with the maximum amount of raindrops summed up in the vertical direction between 0-20 min,

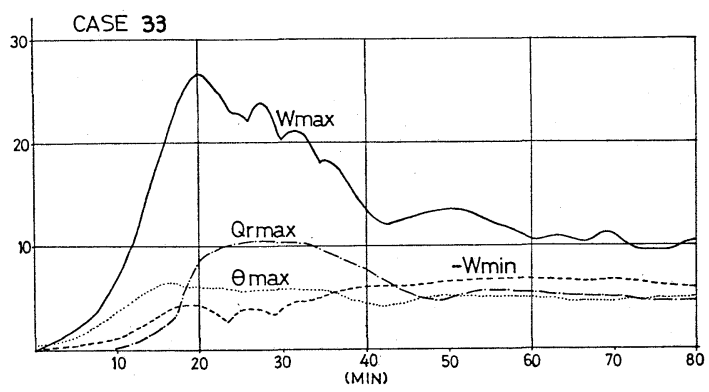

Fig. 13 As in Fig. 4 except in case 33.
20-40 min, 40-60 min and $60-80 \mathrm{~min}$, respectively. It is seen that the vector $e_{3}$ deviates much from the others. In Fig. 12(c) are shown the wind hodograph and the velocity vectors of the position with the maximum amount of raindrops observed at the ground. It is seen that the vector $e_{3}$ deviates rightward against the environmental wind but this deviation is small compared with that in Fig. 12(a).

The life cycle of the convective clouds is shown in Fig. 13. $W_{\max }$ increases to $20.5 \mathrm{~min}$, reaching $26.7 \mathrm{~ms}^{-1}$, then decreases and reaches a quasi-steady state after about $40 \mathrm{~min}$. The other variables show similar trends to those in the cases 21,22 and 31 in the developing stage and soon reach a nearly steady state.

Since an outflow extends to the lateral boundary of the $y z$-plane at $x=0$ after $40 \mathrm{~min}$, upward motions are generated there and increase with time. However, since the cloud we are concerned with is located far from the boundary, calculation is continued until $80 \mathrm{~min}$ when it begins to coalesce into a cloud near the boundary.
C 33

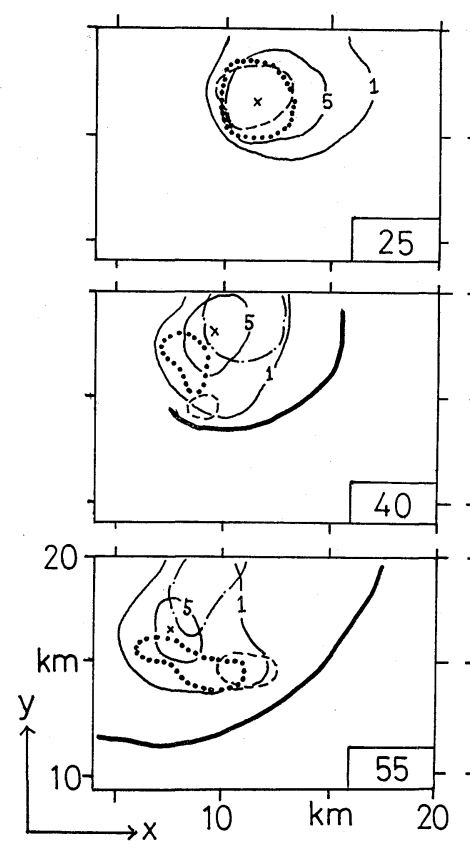

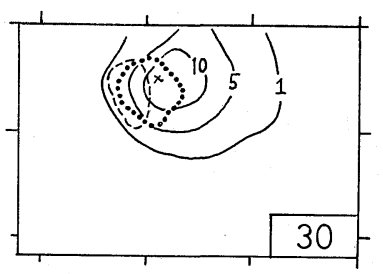
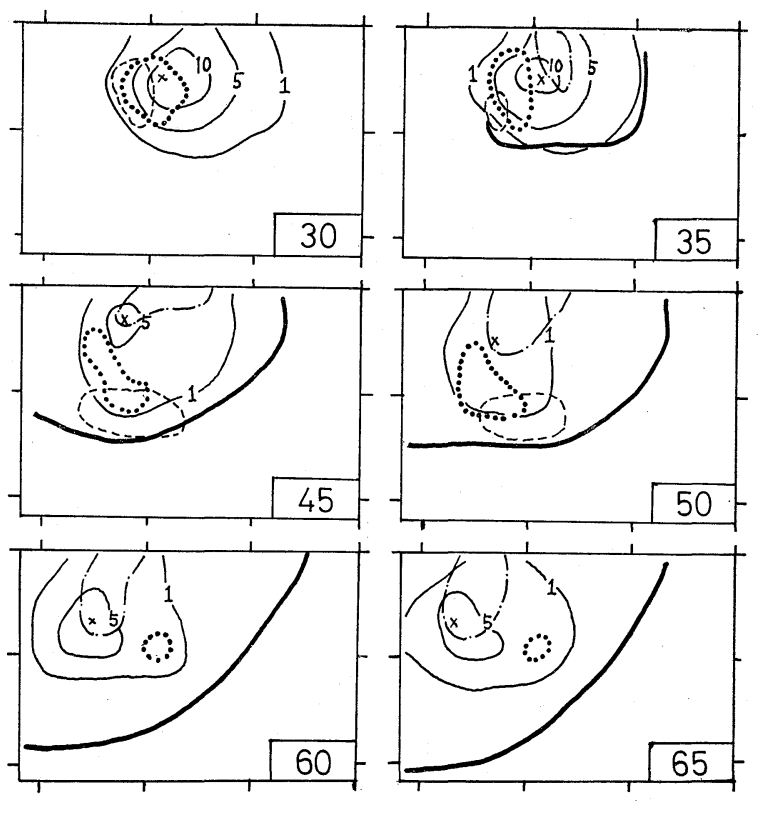

Fig. 14 The contour lines in the $x y$-plane, of $w$ with the value of $5 \mathrm{~ms}^{-1}$ at $z=2.25 \mathrm{~km}$ (thin dashed), of $w$ with the value of $-4 \mathrm{~ms}^{-1}$ at $z=2.25 \mathrm{~km}$ (thin dash-dotted), of $w$ with the value of $10 \mathrm{~ms}^{-1}$ at $z=4.25 \mathrm{~km}$ (dotted) and of the total amount of raindrops summed up vertically in $10 \mathrm{~g} \mathrm{~kg}^{-1}$ (thin solid), and the convergence line at the surface (thick solid). A mark $x$ and a numeral in the lower right corner represent a point with the maximum amount of raindrops and time in minute. 
The process that an updraft changes from downshear tilting to upshear tilting is shown in Fig. 14. Thin dashed, thin dash-dotted, dotted and thin solid lines represent the contour lines of $w$ with the value of $5 \mathrm{~ms}^{-1}$ at $z=2.25 \mathrm{~km}$, of $w$ with the value of $-4 \mathrm{~ms}^{-1}$ at $z=2.25 \mathrm{~km}$, of : $w$ with the value of $10 \mathrm{~ms}^{-1}$ at $z=4.25 \mathrm{~km}$ and of the total amount of raindrops summed up vertically in $10 \mathrm{~g} \mathrm{~kg}^{-1}$, respectively. A thick solid line represents the convergence line at the surface. A mark $\mathrm{X}$ and a numeral in the lower right corner denote a point with the maximum amount of raindrops and time in minute, respectively. The convergence line at the surface is not found until $30 \mathrm{~min}$ and afterwards it is seen on the upstream side of the precipitating region. It shifts to the positive $x$ and the negative $y$ directions with time. The locations of the updraft regions at $z=2.25 \mathrm{~km}$ and at $z=4.25 \mathrm{~km}$ show that the updraft stands upright at $25 \mathrm{~min}$ and tilts slightly downshear in the $x$ direction at 30 min. From $35 \mathrm{~min}$ the updraft region at $z=2.25$ $\mathrm{km}$ moves turning counterclockwise relatively around the downdraft at $z=2.25 \mathrm{~km}$ together with the shift of the convergence line. It is noticed that after 50 min the updraft tilts upshear in the $x$ direction. After $60 \mathrm{~min}$ the updraft at $z=2.25 \mathrm{~km}$ becomes weak and its contour line with the value of $5 \mathrm{~ms}^{-1}$ disappears. The movement of the position with the maximum amount

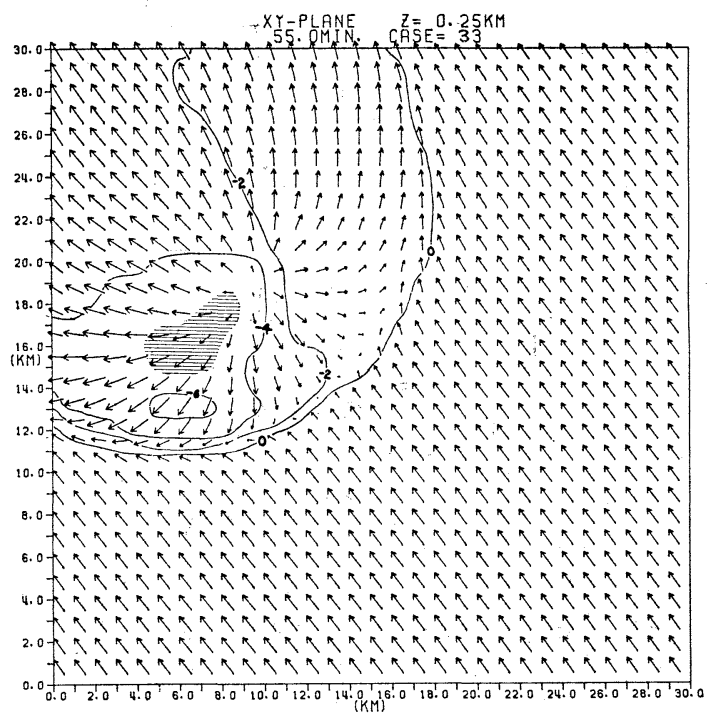

of raindrops coincides with the movement of the rain region, which shifts gradually together with the updraft region. As seen from Fig. 14, the convection pattern in the cloud changes even when the cloud parameters in Fig. 13 have almost constant values.

The convection patterns at $55.0 \mathrm{~min}$ when the cloud parameters in Fig. 13 have nearly constant values are shown in Figs. 15-20. Figs. 15-17 represent the horizontal wind vectors and the contour lines of $\theta^{\prime}, Q_{c}, Q_{r}, \pi^{\prime}, w$ (only in Figs. 16 and 17), horizontal divergence and vertical vorticity in the $x y$-plane at different heights.

Near the surface (Fig. 15) an outflow and a high-pressure cold dome are seen around the precipitating region. The outflow from the precipitating region seems to be a point source flow deformed by the environmental wind. An arcshaped convergence line is found on the upstream side of the precipitating region. This pattern at the surface is in good agreement with the observations at the ground (Foote and Fankhauser, 1973). The magnitude of vertical vorticity is very small compared with that of horizontal divergence.

The convection pattern above the cloud base shown in Fig. 16 is different from that at the surface. The upward motion greater than $2 \mathrm{~ms}^{-1}$ and the downward motion stronger than $-2 \mathrm{~ms}^{-1}$ are found in pairs around the rain region and also near the lateral boundary $x=0$. There is

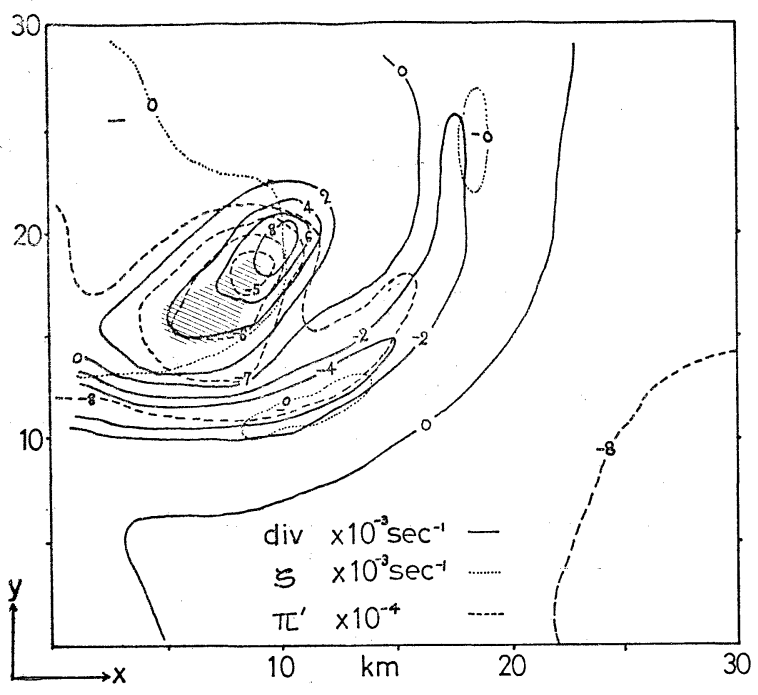

Fig. 15 (a) Contours of $\theta^{\prime}$ (solid) in $K, Q_{0}>0.1 \mathrm{~g} \mathrm{~kg}^{-1}$ (dashed) and $Q r>1.0 \mathrm{~g} \mathrm{~kg}^{-1}$ (shaded) and wind vectors at $55.0 \mathrm{~min}$ at $z=0.25 \mathrm{~km}$ in $x y=$ plane in case 33 . (b) Contours of divergence (solid) in $10^{-3} \mathrm{~s}^{-1}$, vorticity (dotted) in $10^{-3} \mathrm{~s}^{-1}$ and non-dimensional pressure (dashed) in $10^{-4}$. Precipitation region is shaded in (b). 

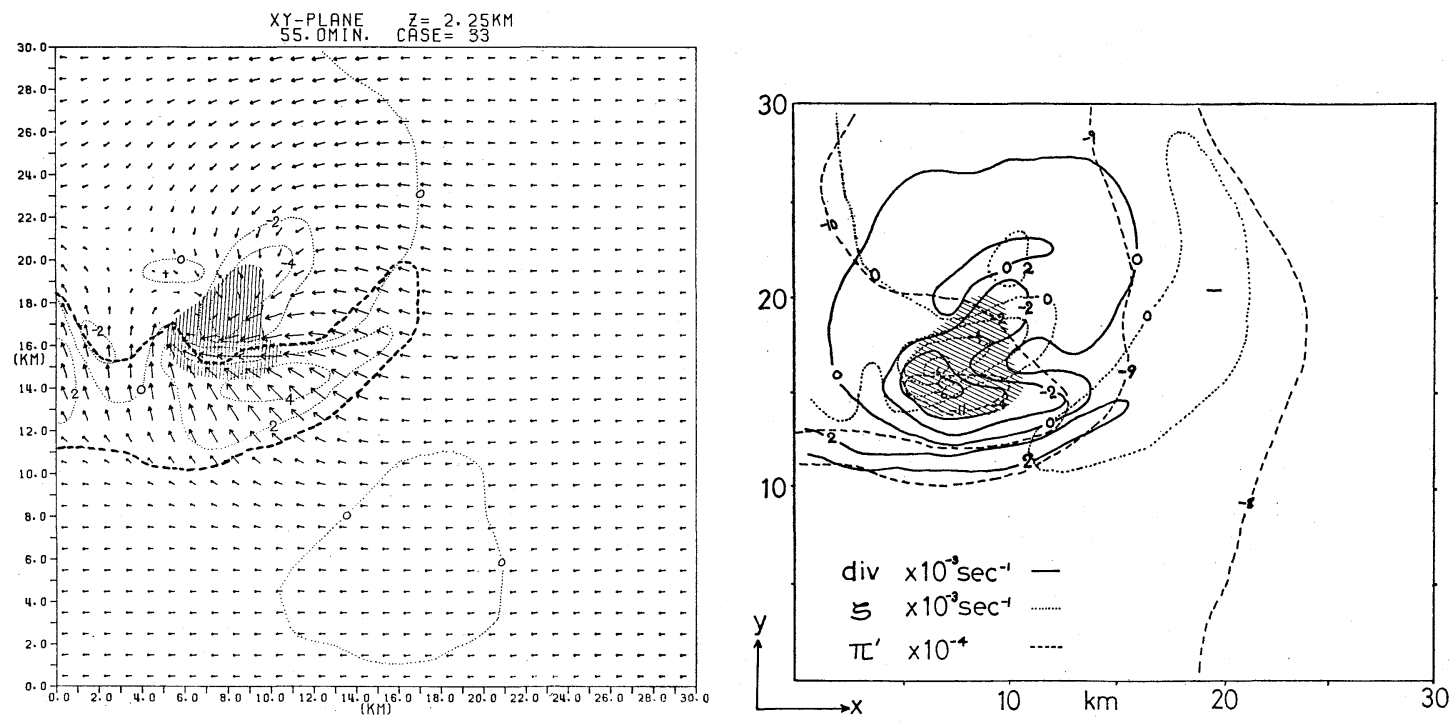

Fig. 16 As in Fig. 15 except at $z=2.25 \mathrm{~km}$ and $w$ (dotted) in $\mathrm{ms}^{-1}$ in (a).

strong convergence in the rain region and weak divergence just above the convergence line at the surface. The anomaly of $\theta^{\prime}$ is less than $2 \mathrm{k}$ and the temperature variation is very small, though there occur condensation and evaporation processes.

Fig. 17 shows the convection pattern at $z=$ $4.25 \mathrm{~km}$. A strong updraft is found in the rain region and weak downward motion around it. There exists a large positive anomaly of $\theta^{\prime}$ in the rain region.

It is noticed from Figs. 15-17 that the rain region becomes wide with height and its over-

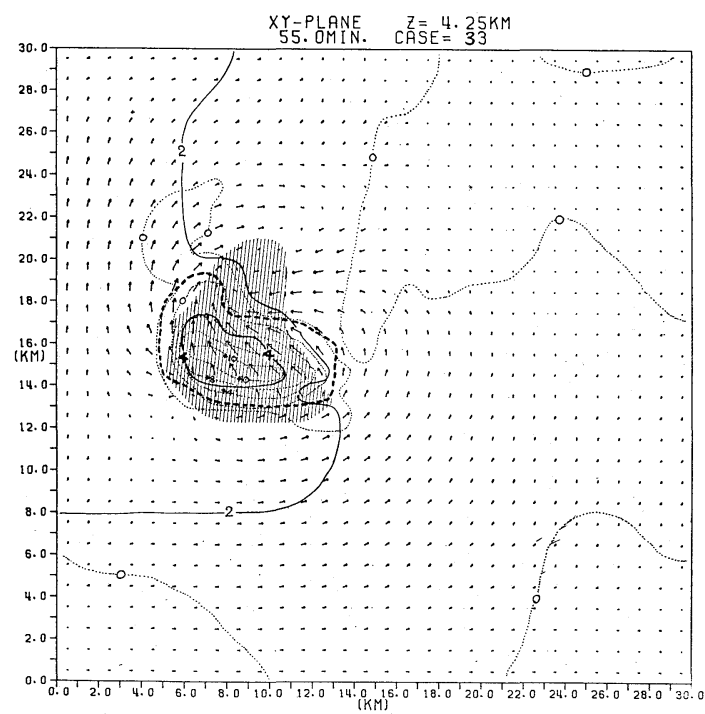

hanging over the lower inflow is obvious. There are a pair of strong anticyclonic and weak cyclonic vortices and the minimum value of vertical vorticity at $z=2.25 \mathrm{~km}$ is found between the updraft and the downdraft regions. The result that the vortex axes are located between the updraft and downdraft coincides with the observational studies by Doppler radar (Kropfli and Miller, 1976; Ray, 1976).

Figs. 18 and 19 show the wind vectors and the contour lines of $\theta^{\prime}, Q_{c}$ and $Q_{r}$ in the $x z-$ planes at $y=14.5 \mathrm{~km}$ where the upward motion is dominant in the rain region at $z=2.25 \mathrm{~km}$ and at $y=17.5 \mathrm{~km}$ where the downward motion predominates, respectively. At $y=14.5 \mathrm{~km}$ (Fig. 18)

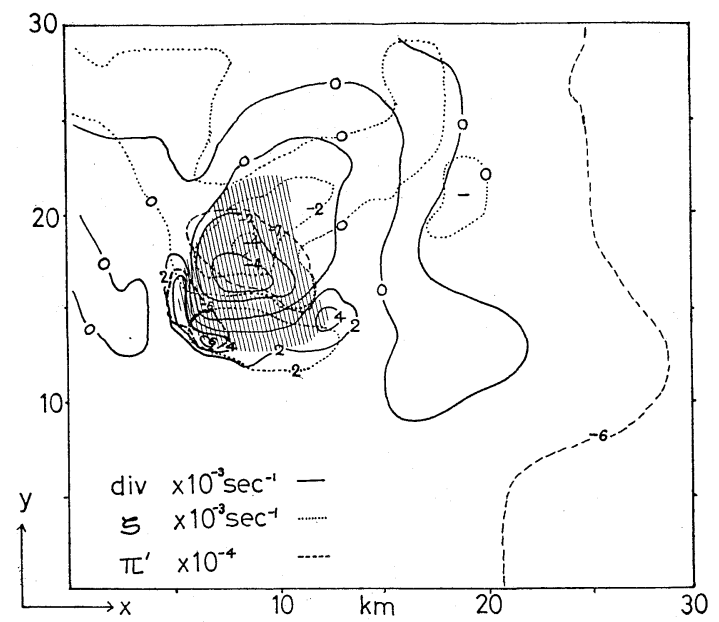

Fig. 17 As in Fig. 16 except at $z=4.25 \mathrm{~km}$. 


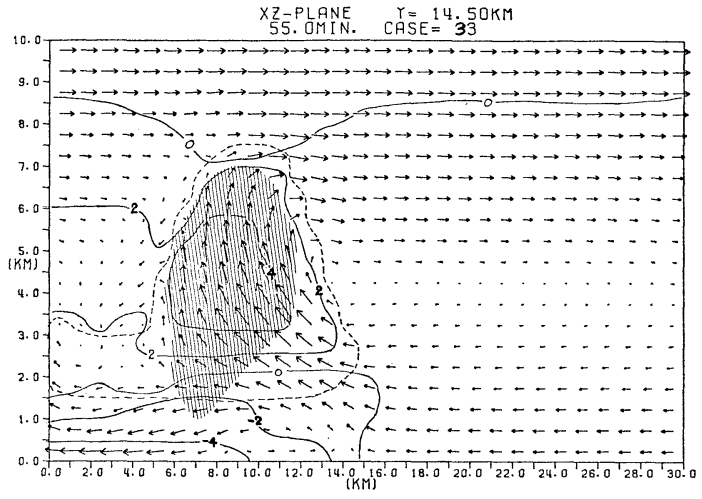

Fig. 18 As in Fig. 10 except at $55.0 \mathrm{~min}$ at $y=14.5 \mathrm{~km}$ in the $x z$-plane in case 33 .

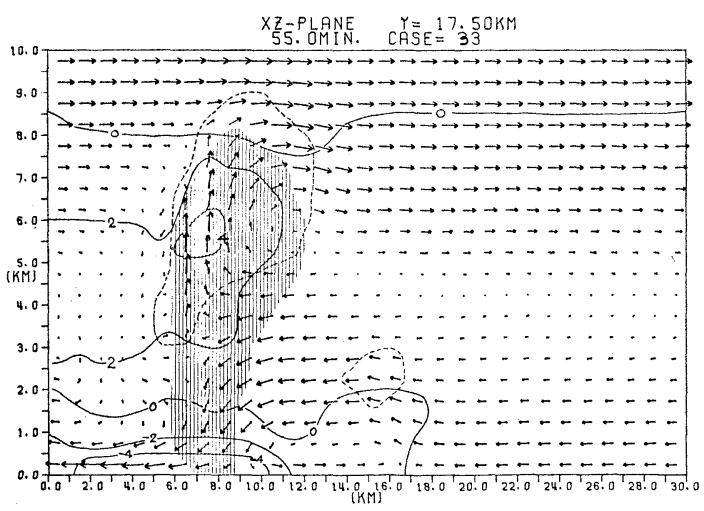

Fig. 19 As in Fig. 18 except at $y=17.5 \mathrm{~km}$.

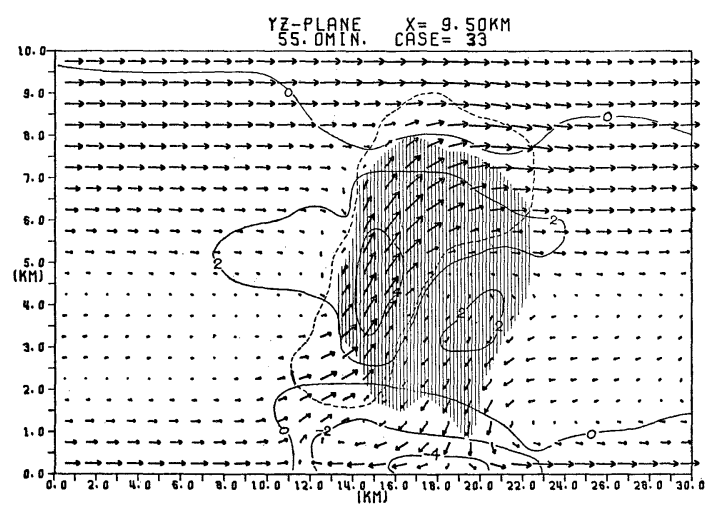

Fig. 20 As in Fig. 18 except at $x=9.5 \mathrm{~km}$ in the $y z$-plane.

there exist a cold dome in the subcloud layer and above it a large cloud with a large positive value of $\theta^{\prime}$ and an updraft. Upshear tilting of the updraft in the linear shear direction, which is not found in cases 21 and 31 , is seen in this $x z$ plane. However, a remarkable downdraft is not found in this plane. At $y=17.5 \mathrm{~km}$ (Fig. 19)
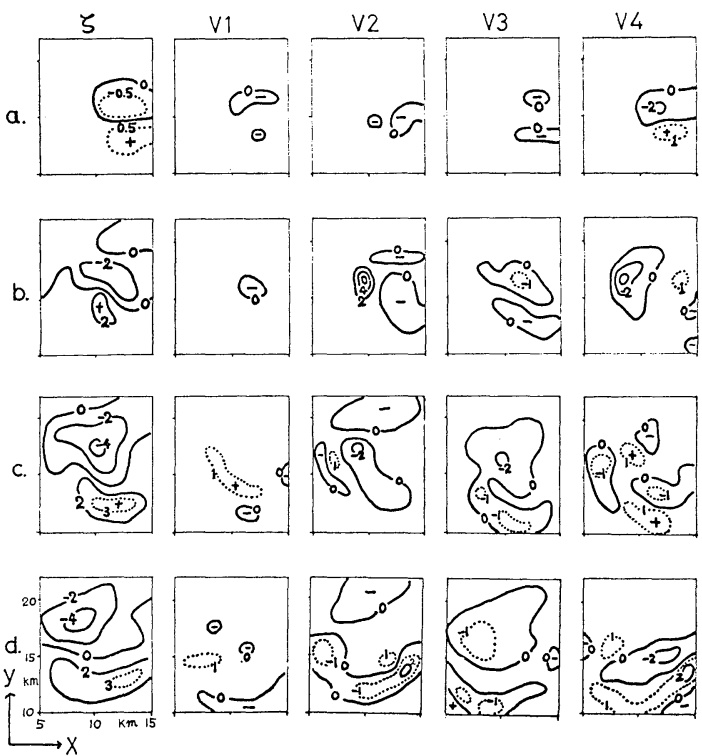

Fig. 21 The horizontal distributions of vertical vorticity $\zeta\left(\times 10^{-3} \mathrm{~s}^{-1}\right)$, the horizontal advection V1 $\left(\times 10^{-5} \mathrm{~s}^{-2}\right)$, the vertical advection V2 $\left(\times 10^{-5} \mathrm{~s}^{-2}\right)$, the divergence term V3 $\left(\times 10^{-5} \mathrm{~s}^{-2}\right)$ and the tilting term V4 $\left(\times 10^{-5} \mathrm{~s}^{-2}\right)$ at (a) $12.5 \mathrm{~min}$, (b) 27.5 min, (c) $40.0 \mathrm{~min}$ and (d) $52.5 \mathrm{~min}$, respectively.

similar features are seen about the cold dome and the cloud, but an updraft in the middle layer and a downdraft are very different from those at $y=14.5 \mathrm{~km}$. Upshear tilting of the updraft is no longer seen and instead the downdraft is dominant in this plane. Near the convergence line at $x=16 \mathrm{~km}$ a small cloud is found and it does not develop into a large cloud in this experiment.

The wind vectors and the contour lines of $\theta^{\prime}$, $Q_{c}$ and $Q_{r}$ in the $y z$-plane at $x=9.5 \mathrm{~km}$ are shown in Fig. 20. It is seen that raindrops are transported rightward and then fall down in the downdraft region, and that the cold dome in the subcloud layer intrudes on the upstream side of the precipitating region and apparently behaves as a mountain.

We discuss about formation of vertical vorticity in the cloud. The local time change of vertical vorticity $\zeta$ is derived from (1) as follows,

$$
\begin{aligned}
\frac{\partial \zeta}{\partial t} & =-\left(u \frac{\partial \zeta}{\partial x}+v \frac{\partial \zeta}{\partial y}\right)-w \frac{\partial \zeta}{\partial z}-\zeta\left(\frac{\partial u}{\partial x}+\frac{\partial v}{\partial y}\right) \\
& +\underbrace{\left(\frac{\partial w}{\partial y} \frac{\partial u}{\partial z}-\frac{\partial w}{\partial x} \frac{\partial v}{\partial x}\right)+K \nabla^{2} \zeta}_{\mathrm{V} 1}|\mathrm{~V} 2| \mid(17)
\end{aligned}
$$


where $\zeta=\partial v / \partial x-\partial u / \partial y$ and V1, V2, V3, V4 and V5 denote the horizontal advection, the vertical advection, the divergence term, the tilting term and the diffusion term, respectively. The horizontal distributions of $\zeta, \mathrm{V} 1, \mathrm{~V} 2, \mathrm{~V} 3$ and $\mathrm{V} 4$ at $z=4.25 \mathrm{~km}$ are shown in Fig. 21 ; (a) at $12.5 \mathrm{~min}$, (b) at $27.5 \mathrm{~min}$, (c) at $40.0 \mathrm{~min}$ and (d) at $52.5 \mathrm{~min}$, respectively. The solid lines are drawn at every $2 \times 10^{-3} \mathrm{~s}^{-1}$ in $\zeta$ and at every $2 \times 10^{-5} \mathrm{~s}^{-2}$ in V1, V2, V3 and V4. The diffusion term V5 is neglected because it has an order of $10^{-6} \mathrm{~s}^{-2}$. A pair of anticyclonic and cyclonic vortices are found and become strong till $20 \mathrm{~min}$, reaching a state with a nearly constant value afterwards. In the developing stage the tilting term V4 is dominant in vorticity budget and the other terms are not important. At $27.5 \mathrm{~min}, \mathrm{~V} 4$ works so as to increase the absolute value of $\zeta$ in the anticyclonic vortex, while the vertical advection V2 does so as to decrease it. The maximum absolute value of $\mathrm{V} 4$ is less than that of $\mathrm{V} 2$ at this time. Afterwards V2, V4 and the divergence term $\mathrm{V} 3$ are dominant in vorticity budget and their horizontal distributions become complex. Since the horizontal wind is weak at this level, the horizontal advection V1 is not so important in vorticity budget. When we see this vortex motion on the coordinate system such as Fig. 12(c), V1 becomes more important on account of the strong horizontal wind. While V3 does not have a large absolute value compared with V2 and V4 at this level, V3 becomes a principal term in vorticity budget near the cloud base at some times.

Some further considerations are made about the results in case 33 . After $35 \mathrm{~min}$, the updraft region separates from the downdraft region and the convergence line, which is connected to the updraft region, always exists on the upstream side of the downdraft region in the subcloud layer. In such a situation an inflowoutflow system is accomplished as follows. 1) Raindrops produced in the updraft region are transported by the wind and then fall down. 2) The downdraft due to raindrops reaches the surface and an outflow is generated in the subcloud layer. 3) This outflow and the environmental wind produce the convergence line on the upstream side of the precipitating region. 4) Along the convergence line fresh air is supplied into the updraft region from the subcloud layer and raindrops are produced again. In this way the convective cloud is long-lasting without any serious decay. In this case there are not seen any quiet periods in the activity of the convective cloud unlike Hane's results. In the inflow-outflow system raindrops falling in the downdraft region do not cut off the supply of fresh air from the subcloud layer into the updraft region. In cases 21 and 31 falling raindrops cut it off. Therefore, the role of the wind with the jet type profile is very important in this system.

In the linear shear wind upshear tilting of an updraft occurs temporarily in the two-dimensional model when a new convective cloud develops in the upshear side of the original cloud, since raindrops produced aloft fall down on the upstream side of the updraft region in the subcloud layer and cut off the supply of fresh air into the updraft region. In case 33, however, upshear tilting of the updraft does not need development of new clouds and may be possibly maintained for a long time, since raindrops produced aloft can be transported not only to the $x$ direction but also to the $y$ direction and fall down on the downstream side of the updraft region in the subcloud layer owing to the jet type wind.

The small deviation of the rain region movement from the environmental wind is seen between $40 \mathrm{~min}$ and $60 \mathrm{~min}$. It is mainly due to the displacement of the long-lasting convective cloud to the negative $y$ direction. As seen in Fig. 14 the updraft region in the cloud moves following the convergence line at the surface. Therefore, the long-lasting convective cloud might shift apparently to the direction in which strong convergence exists in the subcloud layer. The deviation of the rain region movement from the environmental wind might be attained in this way.

\section{c. Some remarks}

As mentioned in the introduction, the environmental atmosphere in which severe storms are imbeded usually has the stratification unstable enough for the convective cloud to be maintained and the strong wind shear consisting of the linear shear in one direction and the jet profile in the other direction. When the jet type wind profile is observed, the long-lasting convective cloud may be possible without any development of new clouds as shown in case 33 and by Takeda (1971). When the linear shear wind is strong, continual formation of new convective clouds may occur as shown in the two-dimensional model by Hane (1973). Severe storms observed actually may be maintained for a long time both through successive activity of a convective cloud and through continual formation of new clouds. 
In this experiment the updraft at $z=2.25 \mathrm{~km}$ becomes weak after $60 \mathrm{~min}$ as shown in Fig. 14, while the cloud parameters in Fig. 13 are almost constant until $80 \mathrm{~min}$. The deviation of the rain region movement from the environmental wind is not also obtained after $60 \mathrm{~min}$. One of reasons for these problems may be ascribed to the lateral boundary conditions and the weak shear wind used in this study. Since successive activity of the convective clouds makes the stratification more stable, maintenance of the convective activity may become more difficult in the later time. In order to simulate a long-lasting convective cloud, it is needed to make numerical calculation in a wider domain or in a domain with the inflow of water vapour through the lateral boundaries as used by Hane (1973).

\section{Conclusions}

A numerical model including dynamical and cloud physical processes is formulated in order to simulate some observational evidences concerning severe storms in the North American Continent. The points which should be simulated are (1) generation of a cold dome and a convergence line at the surface, (2) upshear tilting of an updraft, (3) a long-lasting nature of the convective cloud, (4) a right-moving convective cloud and (5) generation of vertical vorticity.

To examine roles of the wind and the high cloud base on a convective cloud, we simulate a convective cloud with the high cloud base in the linear shear wind or in the jet type wind. We make numerical calculation for four cases; (1) the linear type (L-type) wind in two-dimension (case 21$)$, (2) the jet type (J-type) wind in two-dimension (case 22), (3) the $L$-type wind in the $x$ direction in three-dimension (case 31), (4) the mixed wind of the $L$-type in the $x$ direction and the $J$-type in the $y$ direction in three-dimension (case 33).

Since the behaviours of the convective clouds are similar to each other in the developing stage, we discuss mainly about their behaviours after reaching the mature stage. The maximum values or minimum value of the physical quantities such as $W_{\max }, W_{\min }, \theta_{\max }$ and $Q_{r \max }$ monotonically decay in the $L$-type wind such as cases 21 and 31 , while they reach quasi-steady state in cases 22 and 33. Principal results in the two-dimensional models are similar to those of Takeda (1971). However, it is noticed in case 22 that an outflow from the precipitating region is so strong that the convergence line moves far from the original cloud. Cooling due to evaporation of raindrops falling in the subcloud layer provides the mechanism of generation of a cold dome and a convergence line, which was already pointed out by Fujita (1959).

In case 33 for which the basic wind shear turns direction with height, upshear tilting of an updraft in the $x z$-plane, a long-lasting nature of the convective cloud and the small deviation of the rain region movement from the environmental wind direction are obtained. In this case the downdraft due to raindrops does not cut off the supply of fresh air from the subcloud layer into the updraft owing to the jet type wind and the convergence line connecting to the updraft region exists on the upstream side of the precipitating region at the surface. Therefore the inflowoutflow system is accomplished and the longlasting convective cloud is attained. Upshear tilting of the updraft and the small deviation of the rain region movement from the environmental wind direction may arise from successive activity of the convective cloud toward the negative $y$ direction. It is noted that generation of vertical vorticity is mainly created by the tilting term at the developing stage and later the vertical advection, the divergence term and the tilting term become principal terms. A pair of strong anticyclonic and weak cyclonic vortices are found in the rain region.

It is stressed that the combination of the wind shear turning direction with height and the deep subcloud layer is very important for simulating many observational aspects of the severe storms.

\section{Acknowledgements}

The author wishes to express his hearty thanks to Prof. T. Asai of Ocean Research Institute, University of Tokyo for his guidance and suggestions throughout this study. $\mathrm{He}$ is also indebted to Dr. Tsu. Nitta of University of Tokyo for reading manuscripts, to $\mathrm{Mr}$. $\mathrm{K}$. Ishikawa for programing, to Miss C. Okubo for typing and to referees for pointing out mistakes. This work is supported by Scientific Research Fund from the Education Ministry of Japan.

\section{References}

Asai, T., 1965: A numerical study of the air-mass transformation over the Japan Sea in winter. $J$. Meteor. Soc. Japan, 43, 1-15.

Browning, K. A., 1964: Airflow and precipitation trajectories within severe local storms which travel to the right of the winds. J. Atmos. Sci., 
21, 634-639.

, and R. J. Donaldson, Jr., 1963: Airflow and structure of a tornadic storm. J. Atmos. Sci., 20, 533-545.

growth in supercell storms and some implications for hail suppression. Quart. J. Roy. Met. Soc., 102, 499-533.

Charba, J. and Y. Sasaki, 1971: Structure and movement of the severe thunderstorms of 3 April 1964 as revealed from radar and surface mesonetwork data analysis. J. Meteor. Soc. Japan, 49, 191214.

Foote, G. B. and J. C. Fankhauser, 1973: Airflow and moisture budget beneath a northeast Colorado hailstorm. J. Appl. Met., 12. 1330-1353.

Fuịita, T., 1959: Precipitation and cold air production in meso-scale thunderstorms systems. J. Meteor., 16, 454-466.

- 1963: Analytical mesometeorology-a review. Met. Monogr., No. 27, Amer. Met. Soc., 77-128.

1965: Formation and steering mechanisms of tornado cyclones and associated hook echoes. Mon. Wea. Rev., 93, 67-78.

, and H. Grandoso, 1968: Split of a thunderstorm into anticyclonic and cyclonic storms and their motion as determined from numerical model experiments. J. Atmos. Sci., 25, 416-439.

Hammond, G. R., 1967: Study of a left moving thunderstorm of 23 April 1964. ESSA Technical Memorandum IERTM-NSSL, 31, Apr. 1967, $75 \mathrm{pp}$.

Hane, C. E., 1973: The squall line thunderstorm: Numerical experimentation. J. Atmos. Sci., 30, 1672-1690.

Harlow, F. H. and J. E. Welsh, 1965: Numerical calculation of time-dependent viscous incompressible flow of fluid with free surface. Phys. Fluids, 8, 2182-2189.

Kropfli, R. A. and L. J. Miller, 1976: Kinematic structure and flux quantities in a convective storm from dual-Doppler radar observations. $J$. Atmos. Sci., 33, 520-529.

Lilly, D. K., 1975: Severe storms and storm systems: scientific background, methods and critical questions. Pure and Applied Geophysics, 113, 713734.

Marwitz, J. D., 1972a: The structure and motion of severe hailstorms. Part I: Supercell storms. J.
Appl. Met., 11, 166-179.

, 1972b: The structure and motion of severe hailstorms. Part II: Multi-cell storms. J. Appl. Met., 11, 180-188.

1972c: The structure and motion of severe hailstorms. Part III: Severely-sheared storms. J. Appl. Met., 11, 189-201.

- 1973: Trajectories within the weak echo regions of hailstorms. J. Appl. Met., 12, 11741182.

, and E. X. Berry, 1971: The airflow within the weak echo region of an Alberta hailstorm. J. Appl. Met., 10, 487-492.

Newton, C. W., 1967: Severe convective storms. Advances in Geophysics, 12, 257-308.

ments of convective storms, with emphasis on size discrimination in relation to water-budget requirements. J. Appl. Met., 3, 651-668. and - 1975: Movement and propagation of multi cellular convective storms. Pure and Applied Geophys., 113, 747-764.

Ray, P.S., 1976: Vorticity and divergence fields within tornadic storms from dual-Doppler observations. J. Appl. Met., 15, 879-894.

Schlesinger R. E., 1973: A numerical model of deep moist convection: Part 1 . Comparative experiments for variable ambient moisture and wind shear. J. Atmos. Sci., 30, 835-856.

- 1975: A three-dimensional numerical model of an isolated deep convective cloud: preliminary results. J. Atmos. Sci., 32, 934-957.

Soong, S. and Y. Ogura, 1973: A comparison between axisymmetric and slab-symmetric cumulus cloud models. J. Atmos. Sci., 30, 879-893.

Takeda, T., 1965: The downdraft in convective shower-cloud under the vertical wind shear and its significance for the maintenance of convective system. J. Meteor. Soc. Japan, 43, 302-309.

-, 1971: Numerical simulation of a precipitating convective cloud: the formation of a "long-lasting" cloud. J. Atmos. Sci., 28, 350 376.

Wilhelmson, R., 1974: The life cycle of a thunderstorm in three dimensions. J. Atmos. Sci., 31, 1629-1651.

Williams, G. P., 1969: Numerical integration of the three-dimensional Navier-Stokes equations for incompressible flow. J. Fluid Mech., 37, 727-750. 


\section{シア流中における雲底が高い対流雲の数值実験}

\section{吉 崎 正 憲}

東京大学海洋研究所

力学過程と雲物理過程を含んだ数值モデルを用いて, アメリカでょく見られる雷雲の次の点について考察した。 （1）地上で見られる寒気ドームや収束線の生成，（2）上昇流がアップシアに傾く点，(3) 対流活動が長時間持続する 機構，(4) 対流雲の動きの一般風からのずれ，(5) 垂直に軸をるつ渦の生成, 等である。ここでは 2 次元と 3 次元の モデルを使って4つのケースを計算した。その結果，(1) は雲底下で起る雨滴の蒸発による冷却のために特こった。 (2)～(4) に関しては, 風のシアが高さと共に変わる風の場でシミュレートできた。この場合，ジェットプロフィル が重要な役割を果している。(5)、関しては, 最初は立ち上り項が重要であるが, その後は垂直移流項, 発散項, 立ち上り項の 3 つの項が効く事がわかった。中層では正の渦度と負の滑度が雨域に対になって見られた。 